\title{
QUALITY OF FRONT-LINE WORK = HUMAN RESOURCE MANAGEMENT?
}

\begin{abstract}
"Good quality" human resource management is a source of competitive advantage for companies in the field of personal services, especially in customer service.

Customers' opinion of overall service quality is very much influenced by the impression, when they encounter front-line staff. HR management can be regarded as "good quality" if it is able to ensure that staff members working on the front line are professionally and emotionally well-prepared, and committed. It can only perform its function if it is able to adopt a new approach. As an internal service provider it strives to support workers in both meeting corporate requirements and achieving their individual goals. In the case of service companies with networks change inevitably requires giving local management a broader scope of authority in the field of human resource management, as well as preparing local management for carrying out its increasing range of functions.
\end{abstract}

\section{Introduction}

"Good quality" human resource management is a source of competitive advantage for companies in the field of personal services, especially in customer service. Ensuring "good quality", that is efficacy and efficiency, presents a significant challenge to companies in the industry due to the special features of services (heterogeneity, intangibility, perishability, inseparability. Companies that have national or regional branch networks, such as banks, insurance companies, travel agencies or postal service providers, find it even more difficult to meet this challenge. They run a large number of independently functioning premises, branches, or offices (we will collectively refer to them as 'network units' in this paper), where they have to offer well-balanced and high quality services to their customers' satisfaction. It is well-known that customers' opinion of the quality of services is greatly influenced by the impression that they have of front-line personnel as they meet them. To make sure that these companies have satisfied customers, they have to have well-trained, motivated, satisfied, what is more, committed staff.

Network units occupy a pivotal role in the value chain of the above-mentioned companies and they affect the value creating ability of companies in a significant way. However, the fact that a service provider has a large number of network units does not "automatically" generate a competitive advantage for it.

Research has shown that those corporate abilities and traits can turn into competitive advantages that are valuable, rare, inimitable, and non-substitutable.

The above outlined requirements should be met to ensure that the network is not just one important element of the value chain but an actual source of competitive advantage. In this respect, the network is significant as a "tangible" asset, that is as physical infra- structure, but we believe that the role of human resources is far more important in gaining competitive advantage. Therefore, a network can only offer a real competitive advantage if the knowledge of the front-line staff and the organizational knowledge based on this represent a value that is unique and difficult for other companies to imitate. This requires a strong corporate culture, an appropriate selection and training system, efficient incentive and communication systems, and a management team that strives to lead and not just to manage the staff and the company. HR holds a crucial role in creating all these, but shaping corporate culture, designing the above systems, or management development can only take place by involving other corporate functions as well, and in accordance with their needs. HR can perform its function successfully if it defines itself as an internal service provider and adopts this approach in its operations.

Barber and Strack also stress the vital role of HR management when they introduce a new classification of companies and fields of business. They distinguish "people-based", "people-oriented" and "capital-intensive" businesses. "People-based" businesses have significant staff costs, the ratio of which to capital costs is relatively high, and have relatively low expenses related to future revenue generation. They include fields such as postal and express postal services, brokerage and financial services, hospital and hotel management. Barber and Strack claim that in "people-based businesses" HR management is not a simple supporting function but - due to its direct effect on the company's financial results - an essential, "core" business process. [1]

Experts in HR and in related fields of study have developed several comprehensive concepts on what tools, systems and practices can contribute to the "good quality" management of human resources. Companies that understood the need for improvements have made serious efforts to implement them. However, changes

\footnotetext{
* Andrea Bencsik ${ }^{1}$, Judit Fehér ${ }^{2}$,

${ }^{1}$ University of Veszprém, Egyetem u. 10., 8200 Veszprém, Hungary, E-mail: bencsik@gtk.vein.hu

${ }^{2}$ Hungarian Post Office Ltd, Hungary, E-mail: kolkazsu@axelero.hu
} 
in the environment and in the needs of stakeholders - primarily of customers and employees - make it necessary to rethink the efficacy and efficiency of models and real-life practice, as well as the direction of potential improvements. That is why we believe that it is important to present a summary of what typical problems may arise in the management of front-line staff, and what kind of new expectations are presented to companies by changes in the environment.

\section{Human resource management on the front line - factors contributing to HR-problems}

A common classification of HR management tasks distinguishes administrative tasks from "substantive" ones. Administrative tasks include ones related to employees joining or leaving the organisation, transfers, supplying statistical data for payroll processing or for other purposes etc. Substantive activities include the non-administrative tasks of selection, labour retention, development and motivation. It is useful to separate the two fields from the point of view of quality management. Administrative tasks lend themselves well to standardisation and centralisation, whereas substantive HR activities include several tasks that may not be carried out in a centralised way at all, or only with less success.

Human resource management is an extremely complex field, in which specific activities - such as sourcing and retaining the right staff, motivating employees, effective staff development and communication - operate in close interaction, and, due to the intricate interrelationships between them, it is difficult to identify their individual impact and results. For reasons of clarity, however, it is necessary to separate the sub-systems on a theoretical level.

\subsection{Workforce and quality}

One of the key problems of organising customer service - due to its special features - is to manage fluctuations in demand and to determine optimum staffing levels correspondingly.

It is clear that competition requires companies to operate costeffectively. Wages and staff costs are dominant in the cost structure of service companies, so it is easy to understand that companies wish to reduce them. However, too low staffing levels may prove a serious obstacle to providing customer services of the right quality. If the company tries to minimise its staffing levels purely on the basis of economic considerations and not according to the expected service standard, there will certainly be a decrease in the quality of services.

If the labour shortage is only temporary, peaks may be managed by involving back-office staff or by changing the division of labour temporarily. If, however, it becomes permanent, the company will likely face a decrease in quality. Staff may become frustrated, and, after a while, uninterested by endless queues and grumbling customers. Since only indirect methods are available for measuring quality, the company only learns about the quality problems from the decreasing number of customers.

Providing the right quality staff is even more important than having the right number of staff. This may be affected by the pool that is available to a given network unit, that is the number and quality of applicants available when the local management wants to recruit new staff. Front-line work is basically a routine activity in many cases, but it may involve great responsibility in financial or other terms. If this stress factor is not recognised by means of cash or non-cash rewards (in other words, employees are underpaid), front-line jobs will not necessarily be very attractive to jobseekers. The company may be forced to employ candidates who are not sufficiently prepared, which may result in growing staff turnover, and if it wishes to prevent the decrease in quality, it will have to increase the budget for staff development.

The weaknesses of the system of selection may also present a threat to maintaining the desirable quality in customer service. If there are no effective recruitment processes in place and there is a lack of relevant expertise, employees whose personality or moral standing is not appropriate, might be given front-line jobs. On the one hand, this may incur extra costs as the company has to reinforce its monitoring activities. On the other hand, it will definitely damage the image of the company as mistakes made by customer service staff members are difficult to rectify afterwards.

\subsection{The measure of value - performance measurement and motivation}

It is obvious that an essential requirement of "fair" performance evaluation is the establishment of the measurability of performance. The performance of the front line is basically the same as the quality of the interaction between the front-line staff and the customer. It is, however, difficult to present with exact indicators. For want of a better method, companies measure the outcome of the interaction, that is the output of the customer service process (customer numbers, sales figures etc.) and try to obtain information about the performance of the front line in this indirect way.

Undoubtedly, the advantage of using indicators of customer numbers or sales revenues (sales revenue per employee, number of customers, number of repeat customers etc.) is that they are relatively objective. However, when introducing and using such indicators, service companies with networks have to bear in mind the following:

- Target figures, expectations, etc., that is the target values forming the basis of comparison in performance evaluation, have to be properly differentiated (e.g. to allow for different sales potentials).

- All too often companies regard the number of services sold and the revenue from them as the sole measure of performance. If they assess performance and give incentives relying only on such indicators, employees will primarily concentrate on meeting these performance criteria, too. This may very well be favourable in terms of short-term financial indicators, but will not necessar- 
ily contribute to improving quality in the long run. It is a fact, too, that customers have a negative attitude to an overly strong sales orientation.

Indicators related to complaints are often used when appraising the performance of front-line staff members. It was Kotler who pointed out the adverse effects of this practice. The utilisation of the number of complaints in this respect does not assist in achieving the long-term objectives, namely, the elimination of the sources of deficiencies in quality. (If this figure becomes an element of the employees' performance appraisal, they will go to all lengths to prevent customers from making even justified complaints. Consequently, companies will be unable to receive valuable comments from customers.)

The applicability of customer satisfaction as an indicator is also limited. One reason for this is that customers' value judgement of the overall service process, and their opinion of customer service, which is one part of this process, are difficult to separate. A case in point is the survey that has proved that if trains run on schedule, passengers tend to believe that carriages are cleaner, queues in front of railway ticket offices are shorter etc. [2]

Also, customer satisfaction surveys - especially when conducted by service companies operating in mass markets - are usually representative, therefore they are rarely useful in measuring individual performance exactly.

The weight that is given to specific performance indicators depends on the actual company's culture and its strategic goals, as well as on some practical conditions, such as the availability of IT infrastructure that collects and classifies data.

Incentive schemes can only serve their function if they are effective, flexible and able to differentiate. Ensuring flexibility presents a serious challenge mainly to large companies due to the complex nature of the operations of these organisations. No matter what change the company is planning to make, it has to realise that "everything is interrelated", thus a survey of aspects to be affected by the change should be carried out beforehand. Barber and Strack argue the importance of establishing pay differentials at "peoplebased companies" as the performance of individual employees or teams may differ significantly. At such companies, unlike at capitalbased ones, the performance of lower ranking employees can have a direct effect on financial results, therefore performance-based differential pay should be used down to the lowest level of the organisation. [1]

Financial reward schemes may be used to recognise individual, team or company performance, or a combination of these. Individual reward systems may be applied successfully at companies where employees have an actual effect on their job outcomes. What may actually lead to conflicts in the case of front-line staff members is that they feel that factors like product quality, brand or work organisation influence performance to a much greater extent than their own aptitude and efforts, and the size of available commissions are not in line with employee input.
Team-based incentives can offer benefits in several respects. They may have a positive effect on the efficient division of labour between front-line and back-office workers, as well as on the cooperation between front-line staff members, if performance-based motivation is linked to e.g. team sales performance or other teamlevel turnover indicators.

The third type of performance-based incentive schemes is linked to corporate performance. This solution is often used by service companies, too, as there are exact measures for assessing the performance of the company. In this case the difficulty may lie in determining the extent of the contribution of a particular individual or certain groups to corporate-level performance.

If we examine the issue of motivation in broader terms, and look at job satisfaction and internal motivation, too, we can see that the development of these may be hindered by factors related to the job and to the "image" of the job. Front-line staff can pace or plan their work to a relatively small degree, since the company can offset the fluctuations in demand only to a certain extent. There are a lot of routine elements in their tasks, but, at the same time, they have to be prepared to be able to handle customer reactions. Yet, in the informal hierarchy of the company they often rank rather low, which is also reflected in their non-financial rewards.

\subsection{Short- and/or long-term staff development}

Service companies have to place great emphasis on developing emotional competencies when training front-line staff members. Developing such competencies effectively may require totally different training methods than developing professional competencies. The search for solutions has even led to the emergence of extreme trends like bringing religion into education.

In front-line staff development companies have to strike a balance between the requirements of long-term human resource management and short-term cost-efficiency. Although the importance of learning has increased, companies still try to cut staff training budgets on the basis of financial considerations. At the same time, effective problem resolution, what is more, "solution sales" are expected from employees by service providers. To be able to do this, it is not enough for employees to acquire professional knowledge related to e.g. a particular range of products. Employees need to understand and embrace the company's business policy, and they have to be able to make corresponding decisions in the course of transactions with customers. One- or two-day training courses that focus on preparing staff for a specific task do not create the basis for meeting this requirement, yet companies often settle for this solution for financial reasons.

Product innovation in the field of services does not provide a lasting competitive advantage. Services, especially those with low asset needs, may be copied fast, and the advantages that can be gained when launching the product dissolve quickly. Therefore, it is crucial for service companies with networks to introduce their 
new products in the entire network in the shortest time possible To be able to do so, they have to set up a system of knowledge transfer that can provide a large number of staff members with the necessary knowledge in a short period of time.

4. Communication between "higher-ups" and "lower-downs"

Information flows in two directions in internal communication: from network units to corporate head office and its management, and from headquarters and management towards network units. Whatever direction communication follows, the two prerequisites of a proper flow of information are a corporate culture encourag ing dialogue, and an information system supporting this culture. Role culture, which is often characteristic of large organisations, upholds one-way and mostly formalised communication, where the official way of doing things is adhered to and enforced. Communication between corporate headquarters and network units is rendered more difficult by geographical distances, since head office staff can have access to a lot of information indirectly, too.

When interpreting information, the subculture of a specific field is an important factor. In the case of one-way and formal flows of information, management does not get any feedback on how the receivers of the information transferred by management actually interpret it. This fact should be recognised especially by those companies that - due to their size - are inevitably "forced" to transfer information in writing, and frequently in formalised ways.

\section{The expectations of external and internal customers}

HR specialists have developed several new models and practices that chart the course towards "substantive" human resource management, and typically aim at supporting leaders or key personnel individually. Examples include selection processes comprising several rounds, personalised incentive schemes designed to truly meet individual needs, the continuous development of competencies, e.g. with the help of a personal coach, etc. The key role of human resources in customer service and the specific issues outlined above indicate that large service companies should move towards substantive human resource management in this particular employee segment, too. The need for this shift is reinforced by the following noteworthy trends:

- Research findings from McKinsey show that there is an increasing number of jobs in which most of the tasks involve complex problem resolution, and success hinges on employees' co-operation with co-workers and/or customers. Researchers have created three categories on the basis of what kind of interactions are predominant in particular jobs. Jobs where complex interactions are typical belong to the category of "tacit" jobs. "Transactional" jobs are characterised by routine interactions. The third, "transformational" category includes jobs in which employees are involved in industrial activities, such as the extraction or conversion of raw materials. According to the findings of the McKinsey survey there will be an increase in the proportion of "tacit" jobs in the future. That is why it is vital that companies make the necessary arrangements to develop employees holding down such jobs and to increase the efficacy of these employees' work. [3]

- It is a well-known fact that subjectivity cannot be eliminated from the quality assessment of services. Recent surveys have also indicated what an important role emotions play in value judgements. Research by Fleming et al. shows that "emotionally committed" customers feel more attached to and tend to remain loyal to a particular company, and use its services more often than those who are simply "generally satisfied". [4] This means that the emotional abilities of customer service employees become more valuable. On the other hand, it clearly confirms the fact that the work attitude of front-line staff greatly affects quality.

- Looking at the issue from the point of view of the labour market, it can be assumed that the increase in services, and within services primarily in personal services, will increase the demand for labour force, thus improving the bargaining power of service workers. Consequently, companies will have to make more efforts to retain "good quality" workforce.

- Not only external customers but internal customers, that is employees, have become more conscious, too. Employee expectations related to work and the workplace are changing. Though financial incentives are still dominant in most cases, employee satisfaction is affected by multiple complex criteria. Some researchers distinguish between satisfaction and commitment, and argue that it is not enough if employees are satisfied, they should be committed. A survey of ten companies by Fleming et al. showed that the emotional commitment of customers and that of employees reinforce each other at the local level. The financial results of those network units which have above median values - calculated from the entire sample - for customer and employee emotional commitment are three or four times higher than those produced by outlets which have below median values for both indicators. [4]

Companies have to respond to constantly changing employee needs. Drucker points out that „[i]ncreasingly, 'employees' have to be managed as 'partners' - and it is the definition of a partnership that all partners are equal". He argues that partners cannot be given orders, they have to be persuaded. Therefore, managing people is turning into a marketing activity. Marketing is about finding out what the other party wants, what their values and goals are and what they consider to be a result. [5] The success of adopting this approach in practice depends on how well the company can handle individual needs, in other words, what kind of customised solutions it can offer to employees. Satisfying employees' individual needs in the fields of training, motivation or job design is far more difficult and complex at companies that are particularly cost-sensitive and have a large number of employees than at small, knowledge-based companies rendering project-type services. Large service companies cannot avoid embracing the marketing orientation in their human resource management either, and have to try to introduce systems, tools and processes that support this developmental direction.

\section{Marketing and economies of scale in HR}

As Deming puts it, quality, which may also be regarded as the ability of creating value, is primarily a function of the activities of corporate management. Management sets the goals, develops the strategy, decides on allocating resources, establishes the system of operation etc. Deming differentiates two groups of factors affecting quality: general and special causes. It is the task of the manage- 
ment to handle general causes, to eliminate factors causing system failures, whereas employees may only be held accountable for factors under their direct supervision. [6]

If the above principles are applied to service companies with networks and their human resource management, it can be concluded that head office management, and within that HR, may cause system failures in two ways. Firstly, if corporate level systems related to jobs, competencies, performance evaluation, motivation etc. - do not match strategy, or do not meet the needs of internal customers, e.g. the needs of specific arms of the business. Secondly, if management does not create the conditions that are needed to operate HR systems in line with objectives. The first condition to be mentioned is that a properly prepared local management team possessing the right professional and emotional competencies should be put in place. The reason for this is that the effectiveness of HR systems is very much dependent on how they are implemented in specific network units. The management/managers of network units play the role of a bridge between the management of the company and the front line. Corporate systems developed by HR specialists reach employees partly directly, partly through the management of network units. Local managers may "share the contents of a box" that has arrived from corporate management in various ways, in other words, they can transmit the information to subordinates in different ways. Additionally, they can also contribute to the success of HR systems by shaping the local subculture. [7]

Naturally, it is true for human resource management, too, that the feasibility of "customisation" is largely affected by the costs it incurs. Bearing this fact in mind, making progress may be possible by way of providing a "building blocs" service. What marketeers mean by building blocs is that the company does not render "ready-made" services, but develops service modules to satisfy the needs of well-identifiable customer groups. These modules can be mixed and matched with the active participation of the front line so that customers perceive the service rendered to them as unique. To apply this to human resource management: corporate-level, centralised systems should inherently contain "mass customisation", and local management, playing the role of the front line in this context, should be given the chance and the conditions to convert them into individual solutions.

Certain methods that can work cost-effectively due to the fact that they affect a large number of employees doing the same or similar jobs may be adopted when developing the above mentioned corporate-level systems.

Employee satisfaction surveys similar to customer satisfaction measurement could form the starting point for improvements. Anonymity encourages respondents to give honest opinions, and a sufficiently large sample could ensure the representative nature of the survey. The findings of such a survey could provide information for the differentiation of the offers to be made to employees, too.

One of the most important preconditions of providing customised solutions is extensive differentiation. Employees may be segmented according to their jobs, demographic features or, e.g. their motives. There have been reports on large-scale applications, such as the one Tesco, one of the world's leading international retailers, introduced. Several thousand employees were interviewed, or surveyed in others ways to map the company's workforce. Then employees were classified according to their aspirations, work methods, and even lifestyles, and "customised" incentive packages were offered to them accordingly. [8] Naturally, whether this method actually helps to satisfy individual needs depends on how successful the selection of relevant criteria for differentiation was. Cost-efficiency may be reached by differentiating between employee segments in terms of the degree to which the company fine-tunes solutions for them. Marketing considers establishing customer value as the basis of customer care. Customer value means the degree to which a particular customer or customer segment can contribute to the successful performance of the company in the long run. The value assigned to specific jobs, though, can be calculated according to factors such as the replacement costs of one employee, which should include the actual administrative and training costs as well as elements such as a loss of profits, which may arise from customer defection, or from a fall in revenues during the training period.

Large companies tend to or may actually be forced to apply standardised solutions and more centralisation due to their size, or, possibly, their technology and strategy. However, the selection of employees, the evaluation of their performance, as well as motivating them are based on a lot of information or even impressions that emerge locally and are very difficult to specify, therefore they may only be utilised in decisions made at the local level. Consequently, HR management can make its activities more effective if it trusts the local management and provides it with the right degree of independence.

It is essential, of course, to prepare local management for this task, and to develop tools that support execution. Supporting tools may include, e.g. software for wages management, methodology for selection, or, as a matter of fact, a network of HR specialists the local management can turn to for support when in need. Although developing or creating them may incur considerable costs in some cases, due to the large number of potential users economies of scale may be reached once they are used.

The success of human resource management thus largely depends on whether or not the local management has the authority to make the necessary decisions, and whether it is properly prepared to do so. A broader scope of authority makes it possible to use special information that is not quite available for "higher-ups", it reduces reaction time, and increases the sense of responsibility for decisions made, too. A prerequisite for providing a broader scope of authority is that those who are assigned such authority should have the right skills, abilities, in sum, the professional, intellectual and emotional competencies. 


\title{
References
}

[1] BARBER, F., STRACK, R.: The Surprising Economics of a „People Business”, Harvard Business Review 2005, June.

[2] NEELY, A., ADAMS, C., KENNERLEY, M.: The Performance Prism - The Scorecard for Measuring and Managing Business Success, Pearson Education Limited/2002

[3] BEARDSLEY, S., JOHNSON B., MANYIKA, J.: Competitive advantage from better interactions, The McKinsey Quarterly/2006/2

[4] FLEMING, J. H., COFFMANN, C., HATER, J. K.: Manage Your Human Sigma, Harvard Business Review 2005, July-Aug.

[5] DRUCKER, P. F.: Management Challenges for the 21st Century, Harper/Collins Publisher, NY, 1999.

[6] TENNER, A. D., DETORO, I. J: TQM: three steps to continuous improvement, Addison-Wesley Publishing Company, Inc, 1992.

[7] HUSELID, M. A., BEATTY, R. W., BECKER, B. E.: A players or positions, Harvard Business Review /2005 Dec.

[8] KANTOR, R.: Human Resources in the 21st Century, Wiley, 2003.

\section{University of Žilina Faculty of Special Engineering Department of Technical Sciences and Informatics}

organizes

The $9^{\text {th }}$ scientific conference with international participation

\section{LOGVD-2006}

\author{
Transport Logistics and Crisis Situations
}

Žilina, 21 ${ }^{\text {st }}$ September 2006

Main issues

Informatics and communication technology in logistics support of solving crisis situation Management of transport logistics in crisis information under specific conditions Security and protection of health in crisis situation in transport infrastructure

Theory and practice in management of transport logistics

Solving crisis situations in transport infrastructure

Security of transport in case of evacuation

Security transport of dangerous materials

Logistics support of crisis situations

\section{Secretary of conference}

Ing. Monika Penteková

Fakulta špeciálneho inžinierstva ŽU

UI. 1. mája 32, 01026 Žilina

tel.: 041 / 513 - 6851, 6861, 6860, 6850

fax: 041 / 5136620

email: Monika.Pentekova@fsi.utc.sk 